\title{
Ganoderic acid A inhibits proliferation and invasion, and promotes apoptosis in human hepatocellular carcinoma cells
}

\author{
XU WANG, DI SUN, JIANDONG TAI and LEI WANG \\ Department of Colorectal and Anal Surgery, The First Hospital, Jilin University, Changchun, Jilin 130000, P.R. China
}

Received February 2, 2016; Accepted February 14, 2017

DOI: $10.3892 / \mathrm{mmr} .2017 .7048$

\begin{abstract}
Ganoderic acid A (GA-A), a triterpenoid, has been demonstrated to suppress cell proliferation in various cancers, including breast cancer and osteosarcoma. However, its effect on human hepatocellular carcinoma (HCC) remains to be elucidated. The present study aimed to investigate the effect of GA-A on HCC cells in vitro. The HepG2 and SMMC7721 human HCC cell lines were treated with differing concentrations of GA-A for 24, 48 and $72 \mathrm{~h}$. The cell growth rate, cell cycle and apoptosis, migration and invasion were determined using a Cell Counting Kit-8, flow cytometry and transwell assays, respectively. The expression of apoptosis-associated proteins was detected via western blot analysis. GA-A significantly inhibited the proliferation of human HCC HepG2 and SMMC7721 cells in a dose-dependent manner. Furthermore, GA-A induced cell cycle arrest at the G0/G1 phase and apoptosis, and suppressed the migration and invasion of HCC cells. Furthermore, GA-A decreased the expression of cyclin D1 and increased the expression of p21 and cleaved caspase-3. In conclusion, GA-A suppressed the proliferation of human HCC cells in vitro and may act as a promising natural therapeutic reagent in the treatment of $\mathrm{HCC}$.
\end{abstract}

\section{Introduction}

Hepatocellular carcinoma (HCC) is the third leading cause of cancer-associated mortality worldwide (1), and primarily results from chronic hepatitis, nonalcoholic fatty liver disease and other hereditary conditions (2). At present, surgical treatments, including liver resection and transplantation, are effective therapies for patients with early HCC (3). However, there is no effective therapeutic strategy for non-resectable HCC. Multiple chemotherapeutic drugs are extensively used in the treatment of HCC; however, neurotoxic adverse effects

Correspondence to: Dr Lei Wang, Department of Colorectal and Anal Surgery, The First Hospital, Jilin University, 71 Xinmin Street, Changchun, Jilin 130000, P.R. China

E-mail: e6e6e67@163.com

Key words: ganoderic acid A, human hepatocellular carcinoma, proliferation, apoptosis, invasion have resulted in their limited clinical application and efficacy. Therefore, the development of novel and effective agents with minimum adverse effects for the prevention and treatment of $\mathrm{HCC}$ is of primary concern.

Traditional Chinese Medicine (TCM) is used as effective cancer treatment in China $(4,5)$. Ganoderma lucidum, which is a species of Basidiomycete, has been widely used in TCM for the prevention and treatment of a variety of human ailments, including hypertension, chronic hepatitis and immunological disorders (6). The anticancer and immune properties of G. lucidum extracts result in the prevention of oxidative damage and disease (7). Ganoderic acids (GAs) are a class of triterpenoid extracts of G. lucidum, which are potential low-cost therapeutic candidates with a range of properties. At present, $>130$ GAs and associated derivatives have been isolated and identified from G. lucidum $(8,9)$. These identified GAs have received increasing awareness due to their antitumor properties $(10,11)$ and medicinal benefits $(12)$, notably their potent toxicity to tumor cells. It has been reported that GA-X and GA-T may induce apoptosis in human hepatoma and lung cancer cells, respectively $(13,14)$. A recent study additionally demonstrated that GA-Mf and GA-S induced apoptosis in human HeLa cells via a mitochondrial-mediated signaling pathway (15), and arrested the cell cycle in the G1 and S phases, respectively.

Consistent with the effects of GA-S, it was previously demonstrated that GA-A significantly suppressed the growth and invasiveness of breast cancer cells via inhibition of transcription factor activator protein-1 and nuclear factor- $\kappa \mathrm{B}(16)$. In addition, GA-A inhibited cell proliferation, induced apoptosis and suppressed invasion in human osteosarcoma cells in vitro (17). Furthermore, purified GA-A was demonstrated to exhibit a marked apoptotic effect on B-cell lymphoma cells with minimal toxicity to non-malignant B-cells (18). Various studies have demonstrated the underlying mechanisms involved in apoptosis induced by GA-A in cancer cell lines, including release of cytochrome $\mathrm{c}$ into the cytosolic compartment, activity of caspase 3 and 9 and overexpression of B-cell lymphoma-2 associated $\mathrm{X}$ protein $(18,19)$. In addition, GA-A has been demonstrated to enhance the chemosensitivity of HepG2 cells to cisplatin via inhibition of the janus kinase/signal transducers and activators of transcription-3 signaling pathway. The underlying mechanisms of the bioactivity of purified GA-A in $\mathrm{HCC}$ remain to be elucidated.

Therefore, the aim of the present study was to determine the effect of GA-A on human HCC cell proliferation, apoptosis 
and invasion, and elucidate the mechanisms underlying these effects, which will aid in gaining a better understanding of the effects of GA-A so that it may be used as a natural, therapeutic anti-cancer reagent in the future.

\section{Materials and methods}

Reagents. GA-A and dimethyl sulfoxide (DMSO) were purchased from the State Center for Standard Substances (Beijing, China). The GA-A was purified via high performance liquid chromatography to a purity $>96 \%$ (20) and was dissolved in DMSO at the concentration of $50 \mathrm{mmol} / 1$ and stored at $4^{\circ} \mathrm{C}$. Primary antibodies against cyclin D1 (ab134175), caspase-3 (ab2175), p21 (ab109520) and GAPDH (ab8245) were obtained from Abcam (Cambridge, UK).

Cell culture and treatment. The HepG2 and SMMC7721 human HCC cells were obtained from the Cell Bank of The Chinese Academy of Sciences (Shanghai, China). HepG2 cells were cultured in minimum essential medium (MEM) supplemented with $10 \%$ fetal bovine serum (FBS; Gibco; Thermo Fisher Scientific, Inc., Waltham, MA, USA). SMMC7721 cells were maintained in RPMI-1640 (Hyclone; GE Healthcare, Logan UT, UTA) supplemented with $10 \%$ FBS. These cells were incubated at $37^{\circ} \mathrm{C}$ in a humidified atmosphere containing $5 \% \mathrm{CO}_{2}$. Subsequently, the cells of control group were treated with DMSO whereas HepG2 and SMMC7721 cells were exposed to 50, 100, 150, 200, 250 and $300 \mu \mathrm{mol} / 1 \mathrm{GA}-\mathrm{A}$ for 24 and $48 \mathrm{~h}$ (16). In addition, HepG2 and SMMC7721 were exposed to 100 and $75 \mu \mathrm{mol} / \mathrm{l}$ of GA-A for 24,48 and $72 \mathrm{~h}$.

Cell viability assay. To measure the effect of GA-A on cell viability, a Cell Counting kit-8 (CCK-8) assay was applied to HCC cells, as previously described (21). Cells were plated in a 96 -well plate $(6,000$ cells/well) and grew to $80 \%$ confluence. Following 24,48 or $72 \mathrm{~h}$ drug stimulation (75 and $100 \mu \mathrm{mol} / \mathrm{l}$ ), the optical density (OD) of each well was determined using a microplate reader at a wavelength of $450 \mathrm{~nm}$ following incubation with $10 \mu \mathrm{l} \mathrm{CCK}-8$ solution for $2 \mathrm{~h}$ at $37^{\circ} \mathrm{C}$. The half maximal inhibitory concentration $\left(\mathrm{IC}_{50}\right)$ value was calculated by nonlinear regression analysis using GraphPad Prism 5.0 (GraphPad Software, Inc., La Jolla, CA, USA). Each sample was analyzed in triplicate.

Flow cytometric analyses. HepG2 and SMMC7721 cells were treated with GA-A (100 and $75 \mu \mathrm{mol} / \mathrm{l})$ respectively for $48 \mathrm{~h}$. A total of $1.5 \times 10^{5}$ cells were seeded on $6 \mathrm{~cm}$ dishes in 1640 antibiotic-free medium containing $10 \%$ FBS. For cell cycle analysis, the treated cells were collected and washed twice with cold phosphate buffered saline (PBS). Then, the cells were collected and fixed in $70 \%$ cold ethanol overnight at $4^{\circ} \mathrm{C}$, followed by incubation with $50 \mathrm{mg} / 1$ propidium iodide (PI) 100 mg/l RNase A (Sigma-Aldrich; Merck KGaA, Darmstadt, Germany), and $0.1 \%$ Triton $\mathrm{X}-100$ for $30 \mathrm{~min}$ at $37^{\circ} \mathrm{C}$ in the dark. The cells were analyzed by a flow cytometer (BD FACSCalibur System, BD Biosciences, Franklin Lakes, NJ, USA).

For cell apoptosis analysis, cells were harvested, washed twice and resuspended with cold PBS. Then the cells were treated with $5 \mu \mathrm{l}$ Annexin V/fluorescein isothiocyanate
(FITC), and $10 \mu \mathrm{l}$ PI solution, and incubated at room temperature for $10 \mathrm{~min}$ in the dark. The results were analyzed by flow cytometry (BD FACSCalibur System, BD Biosciences) and the experiments were performed in triplicate.

Western blot analysis. For western blot analysis, the cells were exposed to GA-A for $48 \mathrm{~h}$. after GA-A treatment, Harvested cells were then washed and lysed in lysis buffer (1\% NP40, $20 \mathrm{mM}$ Tris, $137 \mathrm{mM} \mathrm{NaCl}, 10 \%$ glycerol and $1 \mathrm{mM}$ phenylmethyl sulfonyl fluoride). Whole cell lysates were extracted with 2X SDS lysis buffer containing $100 \mathrm{mM}$ Tris- $\mathrm{HCl}$ (pH 6.8), 10 mM EDTA, 4\% SDS and 10\% glycine, and centrifuged at $13,000 \mathrm{x} \mathrm{g}$ for $30 \mathrm{~min}$ at $37^{\circ} \mathrm{C}$. Protein supernatant was collected via centrifugation at $15,000 \mathrm{x} \mathrm{g}$ for $15 \mathrm{~min}$. Protein concentration was determined using the BCA protein assay. Each extract, containing $\sim 30 \mu \mathrm{g}$ protein was separated by SDS-PAGE on a $10 \%$ gel, and then transferred to polyvinylidene fluoride membranes for $2 \mathrm{~h}$ at $300 \mathrm{~mA}$. Subsequently, the membranes were incubated with the primary antibodies overnight at $4{ }^{\circ} \mathrm{C}$ following blocking with $5 \%$ non-fat milk in Tris buffered saline (TBS) buffer with $0.05 \%$ Tween-20 for $1 \mathrm{~h}$ at room temperature. The primary antibodies used were as follows: anti-p21 (1:1,000), anti-cyclin D1 (1:800), anti-Caspase-3 (1:1,000) and anti-GAPDH $(1: 1,500)$. The membranes were subsequently incubated with horseradish peroxidase-conjugated secondary antibodies (sc-2054; 1:5,000; Santa Cruz Biotechnology, Inc., Dallas, TX, USA) for $2 \mathrm{~h}$ at room temperature. Immunodetection was performed using Super ECL Detection reagent (Applygen Technologies, Inc., Beijing, China) according to the manufacturer's protocol.

Transwell migration and invasion assay. A total of $2 \times 10^{6}$ SMMC7721 and HepG 2 cells were treated with GA-A (100 and $75 \mu \mathrm{mol} / 1$ respectively), and were resuspended in serum-free Dulbecco's modified Eagle's medium (DMEM; Thermo Fisher Scientific, Inc.) and seeded in the upper chamber. The lower chamber was filled with DMEM supplemented with $10 \%$ FBS at $37^{\circ} \mathrm{C}$ in $5 \% \mathrm{CO}_{2}$ for $24 \mathrm{~h}$. Then, the cells remaining on the upper surface of the filter were removed, and those cells attached to the lower compartment were stained with $0.1 \%$ crystal violet (GenMed Scientifics Inc., Shanghai, China) at room temperature. The cells that had migrated through the membrane were visualized using an inverted microscope (Olympus Corporation, Tokyo, Japan). Migration was assessed by counting the number of stained cells from 10 random fields at x200 magnification. For the cell invasion assay, cells were treated with similar procedures, except that transwell inserts were matrigel-coated. The experiment was performed in triplicate.

Statistical analysis. All statistical data were analyzed using GraphPad Prism 6.0 software and expressed as the mean \pm standard deviation. The differences between groups were evaluated by the two-tailed Student's t- test. $\mathrm{P}<0.05$ was considered to indicate a statistically significant difference.

\section{Results}

GA-A suppresses the cell viability of HCC cells. The CCK-8 assay was used to measure cell growth and proliferation. As 

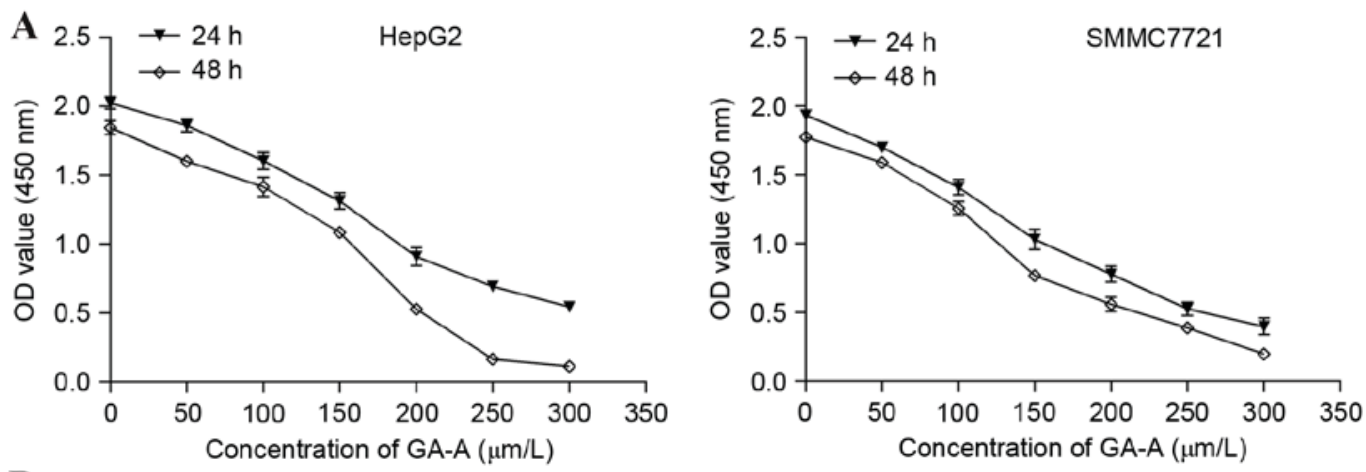

\section{B}
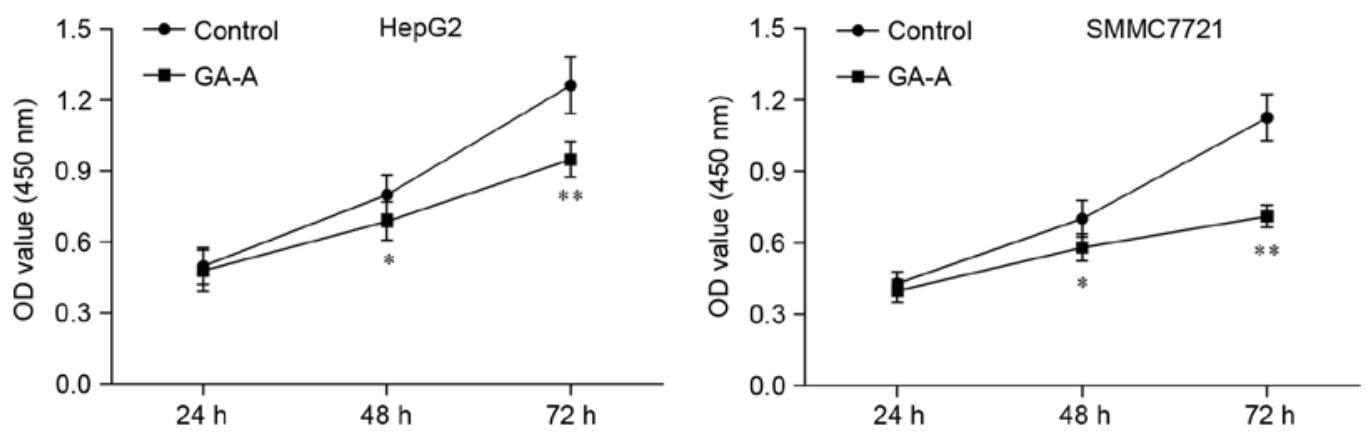

Figure 1. Inhibitory effect of GA-A on the proliferation of HepG2 and SMMC7721 cells determined by a Cell Counting Kit-8 assay. (A) Cells were exposed to different concentrations of GA-A for 24 and 48 h. (B) HepG2 and SMMC7721 were exposed to 100 and $75 \mu$ mol/l of GA-A for 24, 48 and 72 h. Data was expressed as mean \pm standard deviation from triplicate determinations. ${ }^{*} \mathrm{P}<0.05,{ }^{* *} \mathrm{P}<0.01$ vs. control. GA-A, ganoderic acid A; OD, optical density.

presented in Fig. 1A, dose-associated inhibitory effects of GA-A were observed in HepG2 and SMMC7721 cells. The $\mathrm{IC}_{50}$ of GA-A for HepG2 at 24, $48 \mathrm{~h}$ was $187.6,203.5 \mu \mathrm{mol} / 1$, and that for SMMC7721 cells was 158.9 and $139.4 \mu \mathrm{mol} / 1$, respectively. Based on these results, 100 and $75 \mu \mathrm{mol} / 1$ were chosen as the optimal cell treatment concentrations for HepG2 and SMMC7721 cells, respectively. As presented in Fig. 1B, 100 and $75 \mu \mathrm{mol} / 1 \mathrm{GA}-\mathrm{A}$ significantly inhibited the growth of HepG2 and SMMC7721 cells at $48 \mathrm{~h}(\mathrm{P}<0.05)$ and $72 \mathrm{~h}$ $(\mathrm{P}<0.01)$, respectively. Following these observations, 100 and $75 \mu \mathrm{mol} / \mathrm{l} \mathrm{GA}-\mathrm{A}$ for $48 \mathrm{~h}$ was selected as the optimal cell treatment condition for the following assays.

GA-A induces cell cycle progression arrest and cell apoptosis in HCC cells. The effects of GA-A on the HCC cell cycle progression were evaluated by flow cytometry analysis. As presented in Fig. 2A, HCC cells in two groups (control and GA-A) were stained by PI and analyzed by fluorescence-activated cell sorting. Statistical analysis indicated that the percentage of cells in the G0/G1 and G2/mitotic phase was increased in the GA-A group (48.56 and $21.93 \%$, respectively), accompanied by a decrease in the $\mathrm{S}$ phase (29.51\%) compared with control groups (43.43, 18.62 and $37.95 \%$, respectively) in HepG2 cells (Fig. 2B). Additionally, a greater number of cells accumulated in the sub-G1 phase representing early apoptotic cells (Fig. 2C; $\mathrm{P}<0.01$ ). Similar results were obtained for SMMC7721 cells (Fig. 2D and E).

Furthermore, flow cytometry was conducted in order to measure the apoptotic rate in HepG2 and SMMC7721 cells. As presented in Fig. 3A, Annexin V-FITC vs PI plots from the gated cells revealed the populations corresponding to viable
(Annexin V-/PI-), necrotic (Annexin V-/PI+), early apoptotic (Annexin V+/PI-) and late apoptotic (Annexin V+/PI+) cells. Statistical analysis (Fig. 3B) indicated numbers of early apoptotic cells and late apoptotic cells were increased in the GA-A group, compared with control groups in HepG2 and SMMC7721 cells. These results suggested that GA-A induced cell cycle arrest and cell apoptosis.

To further investigate the mechanism underlying GA-A-induced suppressed cell growth, the altered expression of various cell cycle regulators and apoptotic markers was investigated in HCC cells. As presented in Fig. 4, the protein expression of cyclin D1 was decreased in HCC cells treated with GA-A. However, the expression levels of p21 and cleaved caspase-3 were upregulated in HCC cells treated with GA-A compared with controls.

GA-A inhibits the migratory and invasive ability of HCC cells. To investigate the effect of GA-A on migratory/invasive capabilities of HCC cells, a transwell migration/invasion assay was performed on HepG2 and SMMC7721 cells. As presented in Fig. 5A and B, the number of HepG2 and SMMC7721 cells that migrated through the membrane into the lower chamber was significantly decreased in GA-A treatment groups compared with control $(\mathrm{P}<0.01)$. Similarly, GA-A treatment significantly lowered the invasive cell number of HepG2 and SMMC7721 cells compared with the control cells (Fig. 5C and D; P<0.01).

\section{Discussion}

GA-A is a bioactive component extracted from the traditional Chinese medicine TCM, Ganoderma lucidum, which has been 


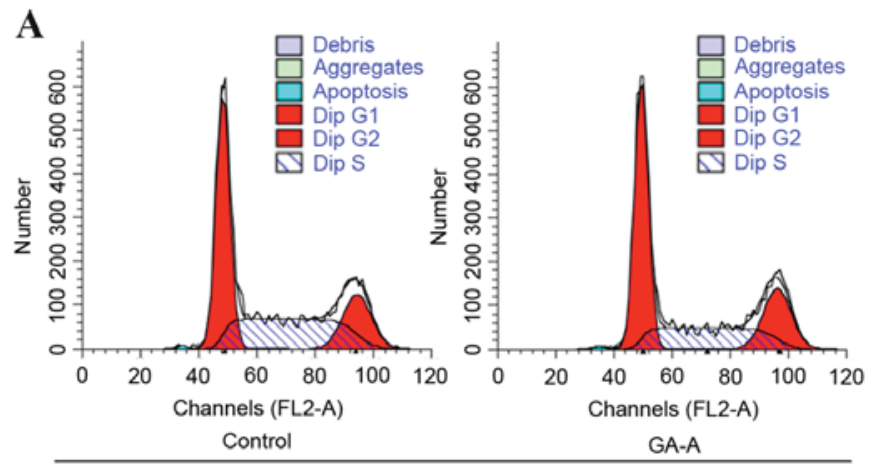

HepG2

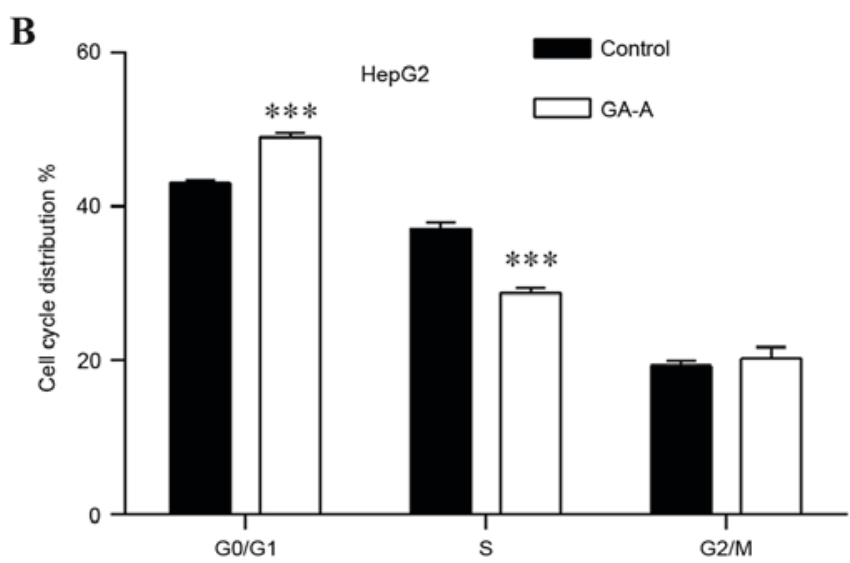

D

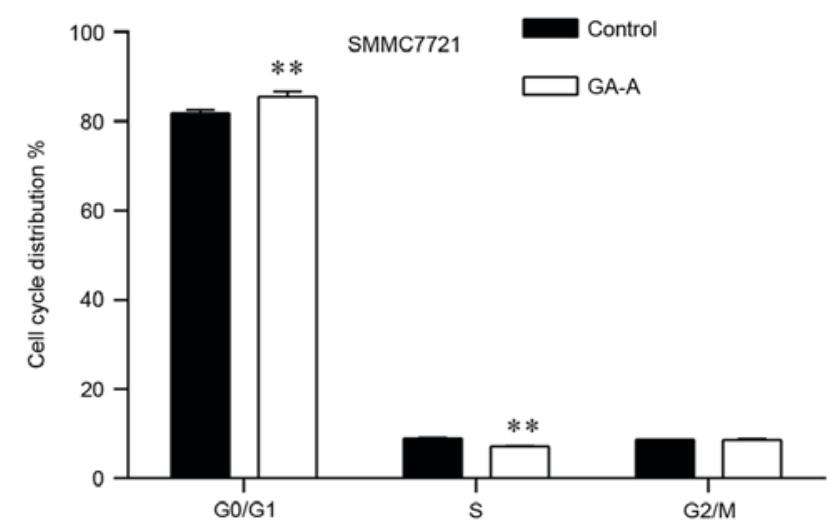

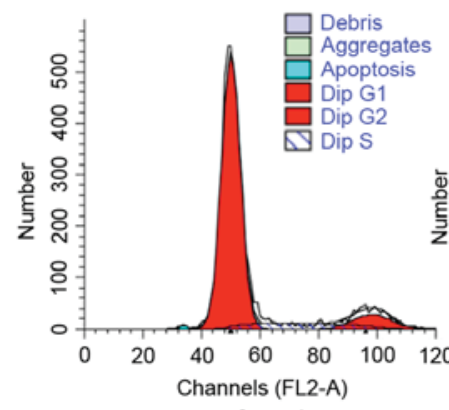

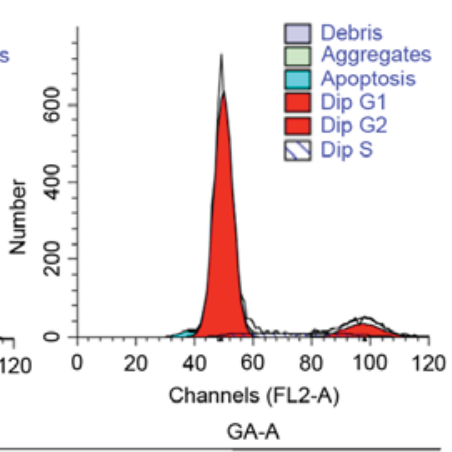

SMMC7721

C

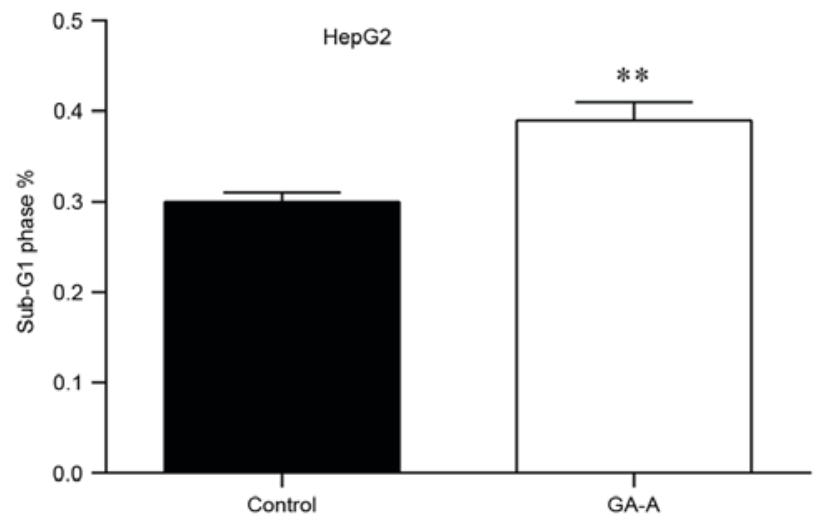

E

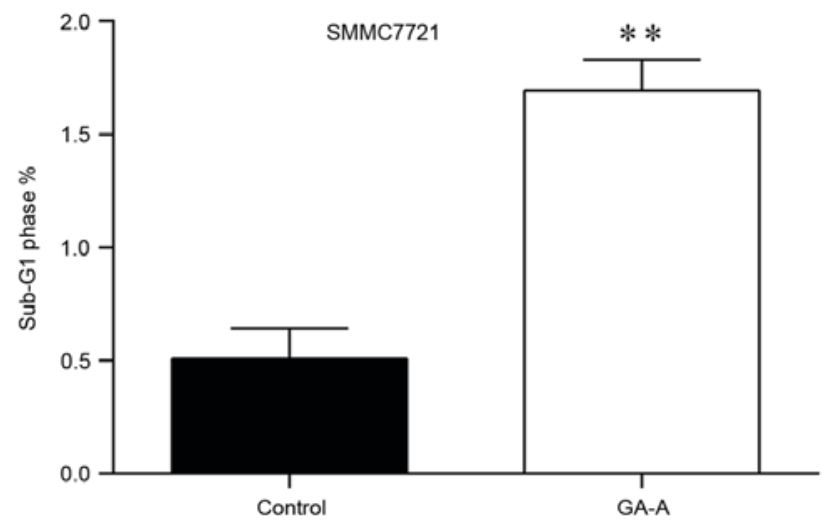

Figure 2. Effect of GA-A on cell cycle distribution of HepG2 and SMMC7721 cells. (A) Flow cytometry analysis of HepG2 and SMMC7721 cells induced by 100 and $75 \mu \mathrm{mol} / 1 \mathrm{GA}-\mathrm{A}$, respectively for $48 \mathrm{~h}$. Comparison of HepG2 cells in (B) G0/G1, S, G2/M phases and (C) sub-G1 phase between the control and treatment groups. Comparison of SMMC7721 cells in (D) G0/G1, S, G2/M phases and (E) sub-G1 phase between the control and treatment groups. Data are expressed as the mean \pm standard deviation. ${ }^{*} \mathrm{P}<0.05,{ }^{* * *} \mathrm{P}<0.01$ and ${ }^{* * * *} \mathrm{P}<0.001$ vs. control. GA-A, ganoderic acid A.

used to treat a variety of diseases including cancer, and which has been considered to be a multitarget agent with antitumor activities. So far, it has been extensively studied with respect to its potential anti-cancer activity in vitro (6). To further elucidate the antitumor mechanism of GA-A, the present study investigated its biological function on human HCC HepG2 and SMMC7721 cells in vitro.

The present study demonstrated that GA-A inhibited proliferation of HCC cells in a dose- and time-dependent manner. GA-A arrested the cell cycle at the G0/G1 phase, induced apoptosis and suppressed invasion of HCC cells in vitro. Consistent with the findings of the present study, GA-A has previously been demonstrated to suppress cell proliferation, colony formation and invasive behavior in breast cancer (16) and osteosarcoma cells (17). Furthermore, western blot analysis revealed that GA-A treatment significantly suppressed the expression level of cyclin D1 and increased the expression levels of p21 and cleaved caspase-3.

A previous suggested that cancer cells exhibit an uncontrolled growth, mediated by abnormalities in cell cycle regulation (22). The cell cycle is modulated by cyclin-dependent kinase (CDK) complexes. Reduction in cyclin D1-CD $4 / 6$ complexes may restrain the progression of G0/G1 to $\mathrm{S}$ phase (23). The results of the present study indicated that GA-A induced cell cycle arrest at the G0/G1 phase via downregulation of cyclin D1. This observation is in agreement with 


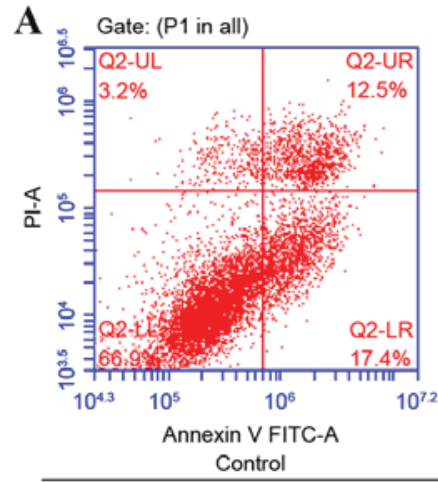

B

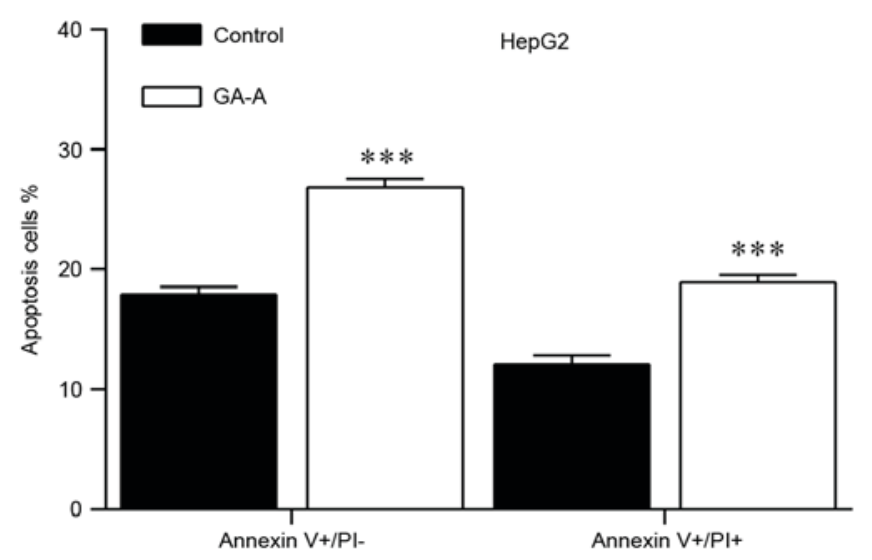

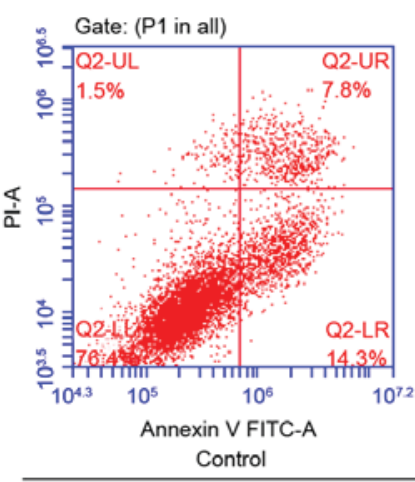

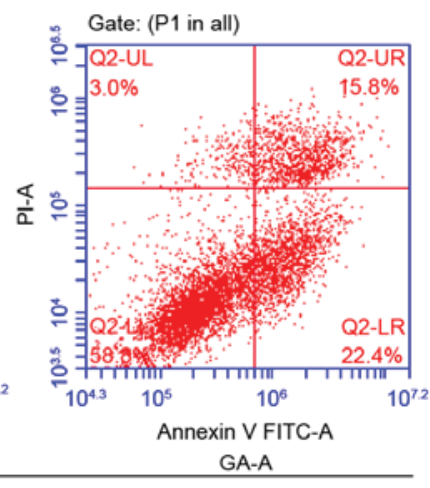

SMMC721

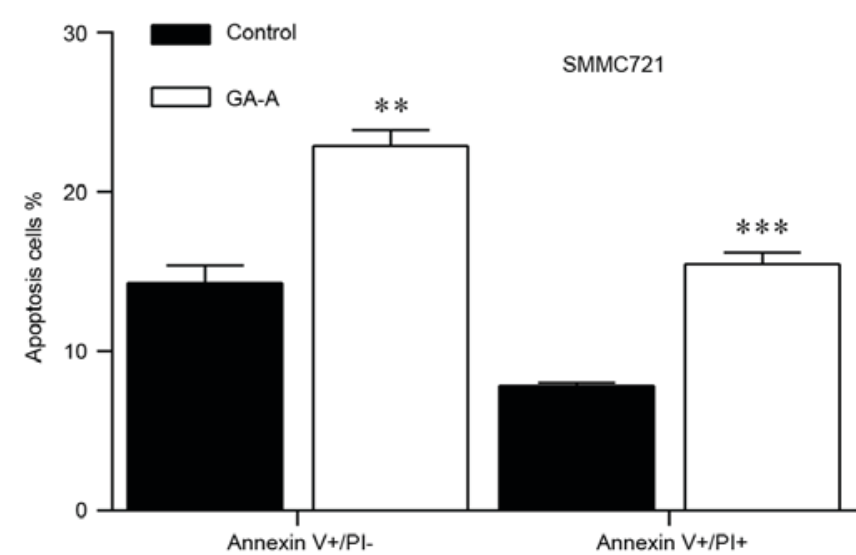

Figure 3. Effect of GA-A on apoptosis in HepG2 and SMMC7721 cells. (A) Flow cytometric analysis of HepG2 and SMMC7721 cells induced by 100 and $75 \mu \mathrm{mol} / 1 \mathrm{GA}-\mathrm{A}$, respectively for $48 \mathrm{~h}$. (B) Statistical analysis of early and late apoptotic rates of HepG2 and SMMC7721 cells between the control and treatment groups. Data was expressed as the mean \pm standard deviation. ${ }^{* *} \mathrm{P}<0.01,{ }^{* * *} \mathrm{P}<0.001$ vs. control. GA-A, ganoderic acid A; PI, propidium iodide.

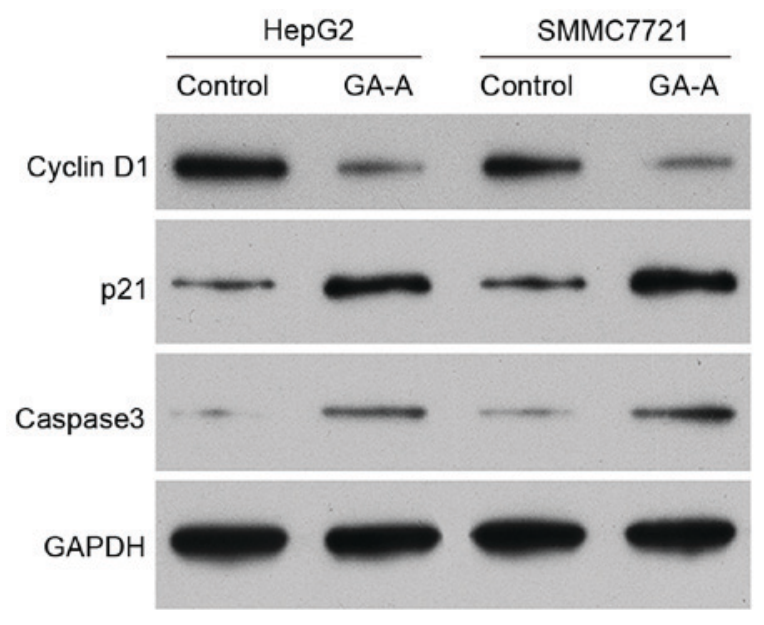

Figure 4. Expression of cell cycle regulators and apoptotic markers. Western blot analysis was used to detect protein expression levels of cell cycle regulators and apoptotic markers in HepG2 and SMMC7721 cells, induced by 100 and $75 \mu \mathrm{mol} / 1 \mathrm{GA}-\mathrm{A}$, respectively, for $48 \mathrm{~h}$. GAPDH served as an internal control. GA-A, ganoderic acid A.

previous reports that GAs disrupt cell cycle progression via downregulation of cyclin D1 in ovarian (24) and breast cancer cells (25). It has additionally been demonstrated that p21 is a broad-acting CDK inhibitor and may promote cell cycle arrest at the $\mathrm{G} 1$ phase by downregulating the cyclin-CDK complex $(26,27)$. Therefore, cell cycle arrest is considered to be a promising strategy in suppressing cancer cell growth, via upregulation of p21 and downregulation of cyclin D1, which may be induced by treatment with GA-A. Apoptosis is the process of programmed cell death and important in maintaining cellular homeostasis (28). The caspase-cascade is important in cell apoptosis and its activation and execution requires a key enzyme, caspase-3 (29). The present study demonstrated the potential induction of cell apoptosis by GA-A via increase of cleaved caspase- 3 protein expression levels, which is similar to the effect of GA-T, which is a chemotherapeutic drug isolated from G. lucidum, on human cervical cancer cells (30). Therefore, the results indicated that activation of the caspase-cascade acts as the mechanism involved in GA-A-induced cell apoptosis in HCC cells.

Cancer metastasis is a multi-step process that includes migration and invasion into surrounding tissues (31), and is the primary cause of mortality in numerous human cancers. The present study observed that GA-A possesses anti-invasive and anti-metastatic functions in HCC cells. Consistent with these results, previous studies have demonstrated that GAs suppress cell migration and invasion of cancer cells. GA-T possessed an inhibitory effect on tumor invasion via inhibition of matrix metalloproteinase expression in colon cancer (32). In lung cancer, GA-Me has been demonstrated to effectively suppress lung metastasis by enhancing immune function in vivo (33). These results suggested that GA-A impacted apoptosis, migration and invasion of HCC cells via alteration of factors associated with their occurrence. 

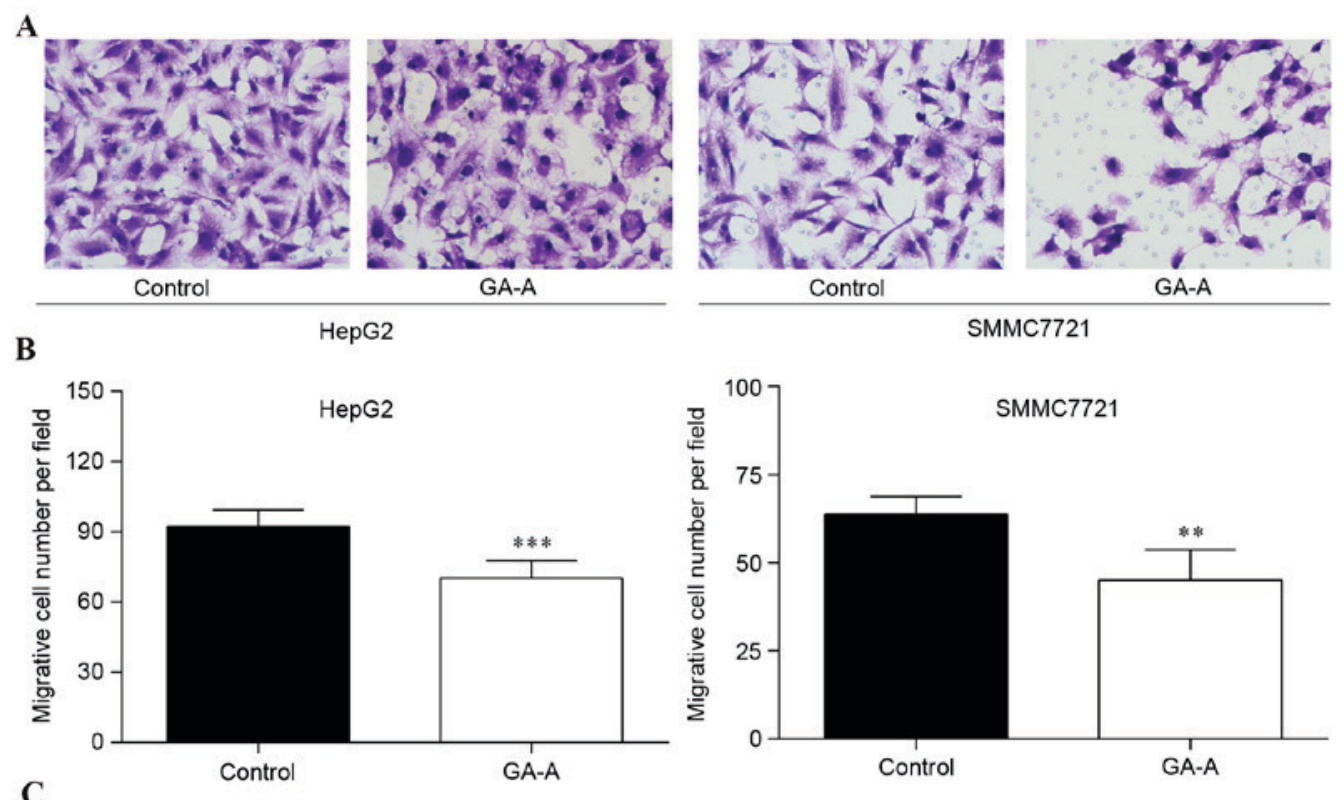

SMMC7721
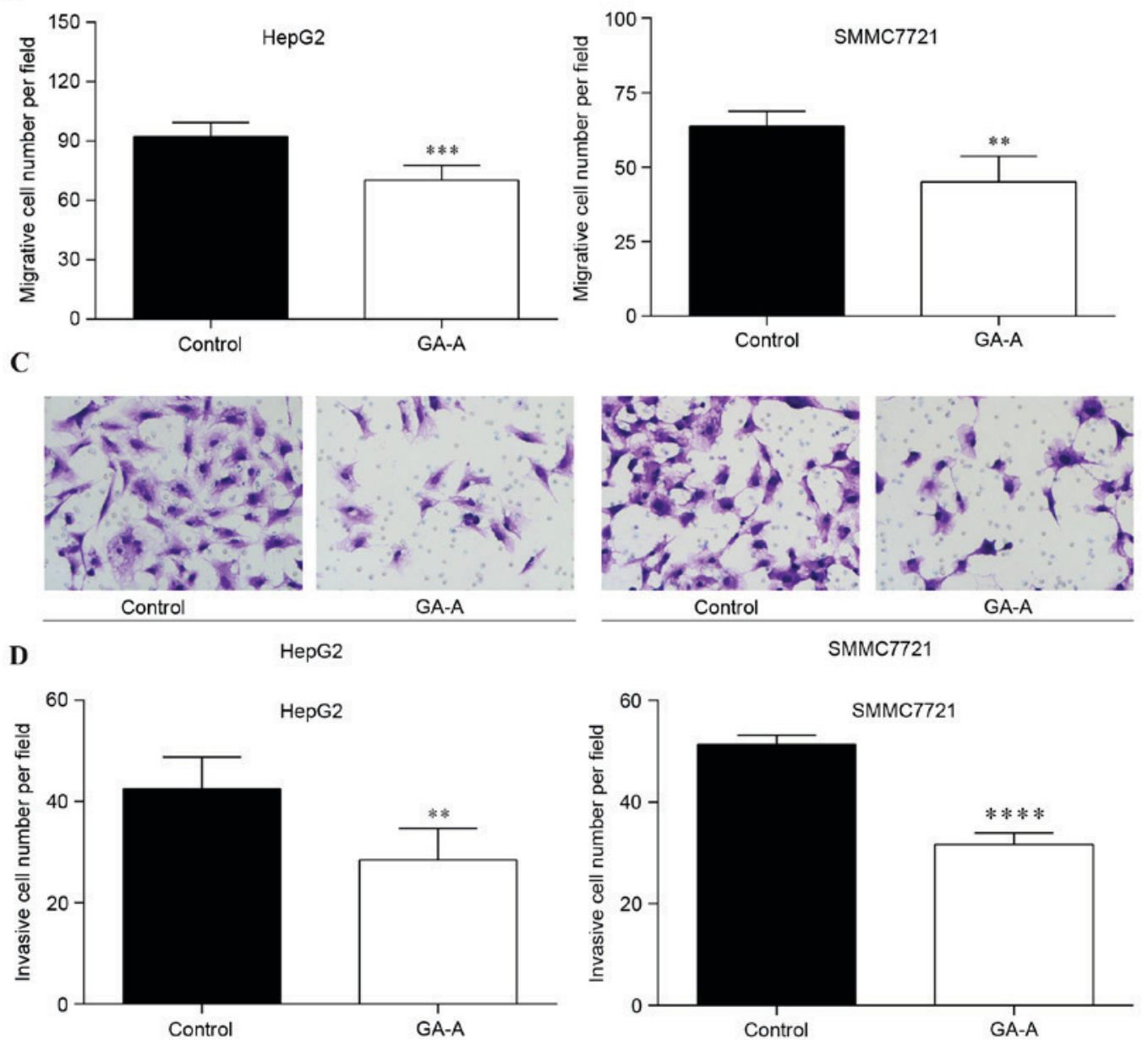

Figure 5. Effect of GA-A treatment on cell migration and invasion. (A) Migratory HepG2 and SMMC7721 cells in GA-A and control groups. (B) Quantitative analysis of migratory HepG2 and SMMC7721 cells per field in the two groups. (C) Invasive HepG2 and SMMC7721 cells in GA-A and control groups (D) Quantitative analysis of invasive HepG2 and SMMC7721 cells per field in the two groups. Data are expressed as the mean \pm standard deviation. ${ }^{* *} \mathrm{P}<0.01$, ${ }^{* * * *} \mathrm{P}<0.001,{ }^{* * * *} \mathrm{P}<0.0001$ vs. control. GA-A, ganoderic acid A.

In conclusion, the results of the present study provide preliminary evidence that GA-A may be applied to HCC as a therapeutic agent. To the best of our knowledge, the present study has been the first to identify that GA-A inhibits HCC cell progression. However, further studies in vivo are necessary to elucidate the exact underlying mechanism of GA-A and aid in its development as a novel and clinical therapeutic anticancer agent in HCC.

\section{References}

1. Firtina Karagonlar Z, Koc D, Iscan E, Erdal E and Atabey N: Elevated hepatocyte growth factor expression as an autocrine c-Met activation mechanism in acquired resistance to sorafenib in hepatocellular carcinom cells. Cancer Sci 107: 407-416, 2016.

2. Bosch FX, Ribes J, Díaz M and Cleries R: Primary liver cancer: Worldwide incidence and trends. Gastroenterology 127 (5 Suppl 1): S5-S16, 2004.
3. Belghiti $\mathrm{J}$ and Fuks D: Liver resection and transplantation in hepatocellular carcinoma. Liver Cancer 1: 71-82, 2012.

4. Luo L, Chen J, Guo S, Wang J, Gao K, Zhang P, Chen C, Zhao $\mathrm{H}$ and Wang W: Chinese herbal medicine in the treatment of chronic heart failure: Three-stage study protocol for a randomized controlled trial. Evid Based Complement Alternat Med 2015: 927160, 2015.

5. Mok TS, Yeo W, Johnson PJ, Hui P, Ho WM, Lam KC, Xu M, Chak K, Chan A, Wong H, et al: A double-blind placebo-controlled randomized study of Chinese herbal medicine as complementary therapy for reduction of chemotherapy-induced toxicity. Ann Oncol 18: 768-774, 2007.

6. Liu X, Yuan JP, Chung CK and Chen XJ: Antitumor activity of the sporoderm-broken germinating spores of Ganoderma lucidum. Cancer Lett 182: 155-161, 2002.

7. Kim KC and Kim IG: Ganoderma lucidum extract protects DNA from strand breakage caused by hydroxyl radical and UV irradiation. Int J Mol Med 4: 273-277, 1999.

8. Luo J and Lin ZB: Advances of pharmacological effects of triterpenes from Ganoderma lucidum. Yao Xue Xue Bao 37: 574-578, 2002 (In Chinese) 
9. Keypour S, Rafati H, Riahi H, Mirzajani F and Moradali MF: Qualitative analysis of ganoderic acids in Ganoderma lucidum from Iran and China by RP-HPLC and electrospray ionisation-mass spectrometry (ESI-MS). Food Chemistry 119: 1704-1708, 2010

10. Lindequist $\mathrm{U}$, Niedermeyer TH and Jülich WD: The pharmacological potential of mushrooms. Evid Based Complement Alternat Med 2: 285-299, 2005.

11. Yuen JW and Gohel MD: Anticancer effects of Ganoderma lucidum: A review of scientific evidence. Nutr Cancer 53: 11-17, 2005.

12. Chen RY and Yu DQ: Studies on the triterpenoid constituents of the spores from Ganoderma lucidum karst. Yao Xue Xue Bao 26 : 267-273, 1991 (In Chinese).

13. Li CH, Chen PY, Chang UM, Kan LS, Fang WH, Tsai KS and Lin SB: Ganoderic acid X, a lanostanoid triterpene, inhibits topoisomerases and induces apoptosis of cancer cells. Life Sci 77: 252-265, 2005.

14. Tang W, Liu JW, Zhao WM, Wei DZ and Zhong JJ: Ganoderic acid $\mathrm{T}$ from Ganoderma lucidum mycelia induces mitochondria mediated apoptosis in lung cancer cells. Life Sci 80: 205-211, 2006.

15. Liu RM and Zhong JJ: Ganoderic acid Mf and S induce mitochondria mediated apoptosis in human cervical carcinoma HeLa cells. Phytomedicine 18: 349-355, 2011.

16. Jiang J, Grieb B, Thyagarajan A and Sliva D: Ganoderic acids suppress growth and invasive behavior of breast cancer cells by modulating AP-1 and NF-kappaB signaling. Int J Mol Med 21: $577-584,2008$

17. Shao J, Li Z, Jiao G, Sun G and Zhou Z: Ganoderic acid A suppresses proliferation and invasion and induces apoptosis in human osteosarcoma cells. Nan Fang Yi Ke Da Xue Xue Bao 35 619-624, 2015 (In Chinese).

18. Radwan FF, Perez JM and Haque A: Apoptotic and immune restoration effects of ganoderic acids define a new prospective for complementary treatment of cancer. J Clin Cell Immunol S3: 4, 2011.

19. Radwan FF, Hossain A, God JM, Leaphart N, Elvington M Nagarkatti $M$, Tomlinson S and Haque A: Reduction of myeloid-derived suppressor cells and lymphoma growth by a natural triterpenoid. J Cell Biochem 116: 102-114, 2015.

20. Tang W, Gu T and Zhong JJ: Separation of targeted ganoderic acids from Ganoderma lucidum, by reversed phase liquid chromatography with ultraviolet and mass spectrometry detections. Biochemical Eng J 32: 205-210, 2006.
21. Yan C, Zhu Y, Zhang X, Chen X, Zheng W and Yang J: Down-regulated aquaporin 5 inhibits proliferation and migration of human epithelial ovarian cancer $3 \mathrm{AO}$ cells. J Ovarian Res 7: 78, 2014.

22. Vermeulen K, Van Bockstaele DR and Berneman ZN: The cell cycle: A review of regulation, deregulation and therapeutic targets in cancer. Cell Prolif 36: 131-149, 2003.

23. Massagué J: G1 cell-cycle control and cancer. Nature 432: 298-306, 2004

24. Hsieh TC and Wu JM: Suppression of proliferation and oxidative stress by extracts of Ganoderma lucidum in the ovarian cancer cell line OVCAR-3. Int J Mol Med 28: 1065-1069, 2011.

25. Li F, Wang Y, Wang X, Li J, Cui H and Niu M: Ganoderic acids suppress growth and angiogenesis by modulating the $\mathrm{NF}-\kappa \mathrm{B}$ signaling pathway in breast cancer cells. Int J Clin Pharmacol Ther 50: 712-721, 2012

26. Stivala LA, Cazzalini O and Prosperi E: The cyclin-dependent kinase inhibitor p21CDKN1A as a target of anti-cancer drugs. Curr Cancer Drug Targets 12: 85-96, 2012.

27. Starostina NG and Kipreos ET: Multiple degradation pathways regulate versatile CIP/KIP CDK inhibitors. Trends Cell Biol 22: 33-41, 2012.

28. Degterev A and Yuan J: Expansion and evolution of cell death programmes. Nat Rev Mol Cell Biol 9: 378-390, 2008.

29. Fan TJ, Han LH, Cong RS and Liang J: Caspase family proteases and apoptosis. Acta Biochim Biophys Sin (Shanghai) 37: 719-727, 2005.

30. Liu RM, Li YB and Zhong JJ: Cytotoxic and pro-apoptotic effects of novel ganoderic acid derivatives on human cervical cancer cells in vitro. Eur J Pharmacol 681: 23-33, 2012.

31. Zhang J, Shen Y, Liu J and Wei D: Antimetastatic effect of prodigiosin through inhibition of tumor invasion. Biochem Pharmacol 69: 407-414, 2005.

32. Chen NH, Liu JW and Zhong JJ: Ganoderic acid T inhibits tumor invasion in vitro and in vivo through inhibition of MMP expression. Pharmacol Rep 62: 150-163, 2010.

33. Chen NH, Liu JW and Zhong JJ: Ganoderic acid me inhibits tumor invasion through down-regulating matrix metalloproteinases 2/9 gene expression. J Pharmacol Sci 108: 212-216, 2008. 